\title{
Design of Communication System of Mine Surveying Robot Based on SCI Module
}

\author{
Yusheng $\mathrm{Li}^{1,2, \text { a }}$, Na Lin ${ }^{1,2}$ \\ ${ }^{1}$ CCTEG Shenyang Research Institute, Fushun Liaoning 113122, China \\ ${ }^{2}$ State Key Laboratory of Coal Mine Safety Technology, Fushun Liaoning 113122, China \\ a Corresponding author Email:651779986@qq.com
}

Keywords: Mines, Robot, SCI, Communication system.

\begin{abstract}
On the basis of analyzing the importance of mine survey work and traditional survey methods, this paper puts forward the communication technology of mine survey robot by using the serial communication (SCI) module of digital signal processor (DSP), introduces the data transmission process and technical characteristics of SCI module in detail, and designs the hardware circuit of communication interface between DSP (TMS320F2812) and driver chip SP3223EEY.
\end{abstract}

\section{Introduction}

Mine surveying is a comprehensive application of multi-disciplinary knowledge, such as surveying, mining, geology and modern power electronic technology, to study various spatial geometric problems in the process of mine geological exploration, construction and mining under static and dynamic conditions. It belongs to an important branch of mining science and is also an important part of mining science. Mine survey is an indispensable basic technical work in the process of mining development, which needs to be carried out in every stage of exploration, design, construction and production, even after the mine is abandoned. With the rapid development of China's economy, mining and industry have also achieved unprecedented development. However, in traditional mine survey, manual methods are adopted, which require staff to rush to the site to measure, view data and analyze and process them. Because the measuring points are distributed in different positions in the mining area, the workload in the measuring process is heavy, which leads to the waste of a lot of human resources. The research of robot communication system for mine survey is of great significance for reducing the workload of mining enterprises, reducing production safety accidents and the safety of life and property in Protect the people. . Mine surveying robot is shown in Figure 1.

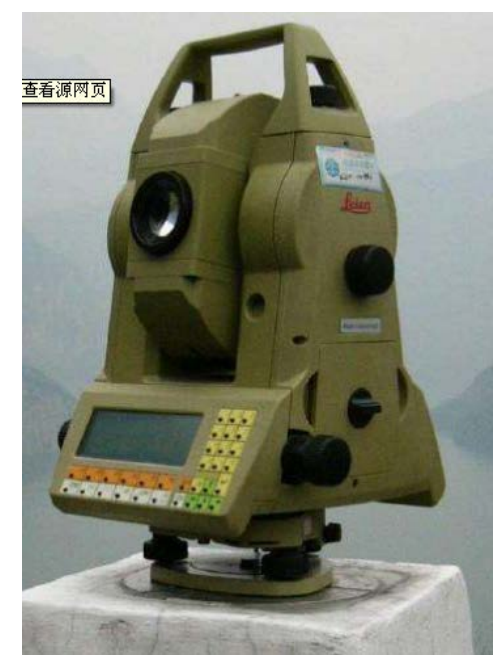

Figure 1 Mine surveying robot 


\section{Mine survey robot}

Mine surveying robot, also known as mine geodesic robot, is a device that replaces traditional manual data measurement. It can automatically search, track and identify targets, and has the functions of target angle monitoring, distance monitoring, three-dimensional coordinate monitoring and image monitoring. Mine survey robot is a video imaging system which integrates stepping motor technology and CCD imaging technology based on electronic total station, and develops advanced control system, communication technology and upper computer data processing software for mine survey robot. Mine measuring robot can quickly identify and judge the measuring target by using high-precision sensors, and automatically complete calibration, reading and other operations, which can completely replace manual measurement. The mine measuring robot can automatically measure according to the measuring cycle, and has the function of precise control of the whole measuring process, and processes and analyzes the data to realize unmanned automatic measurement. The fixed automatic measurement mode and the mobile semi-automatic measurement mode can be selected in the measurement process of the mine measuring robot. The mine survey robot involved in this paper adopts fixed automatic measurement mode.

\section{Communication system design}

The data communication between the mine measuring robot and the upper computer adopts serial communication technology, that is, the serial communication interface module (SCI) inside the DSP is used to send data to the upper computer for data transmission. The communication system structure is shown in Figure 2. The communication system selects TMS320F2812 as the data processing chip, which is composed of TMS320F2812, clock unit, reset circuit, display unit, instruction input unit, alarm unit, communication circuit, etc. SCI module adopts standard non return to zero data format, which can realize data communication between multiple CPUs or with other peripherals with compatible data format SCI port. In order to ensure the integrity of the data, SCI module detects discontinuity, polarity, overrun and frame error. Several explanations of SCI transmitting signal:

(1) bit TXENA goes high, enabling the transmitter to send data;

(2) Write data to the SCITXBUF register, and the transmitter cannot be empty, and the TXRDY bit becomes low;

(3) SCI sends data to shift register;

(4) after TXRDY goes high, the program writes the second character to SCITXBUF register;

(5) After sending the first character, start shifting the second character to the register TXSHF;

(6) TXENA goes low, which prohibits the sender from sending data, and SCI ends the sending of the current character;

(7) When the second character is sent, the sender is empty and ready to send the next character.

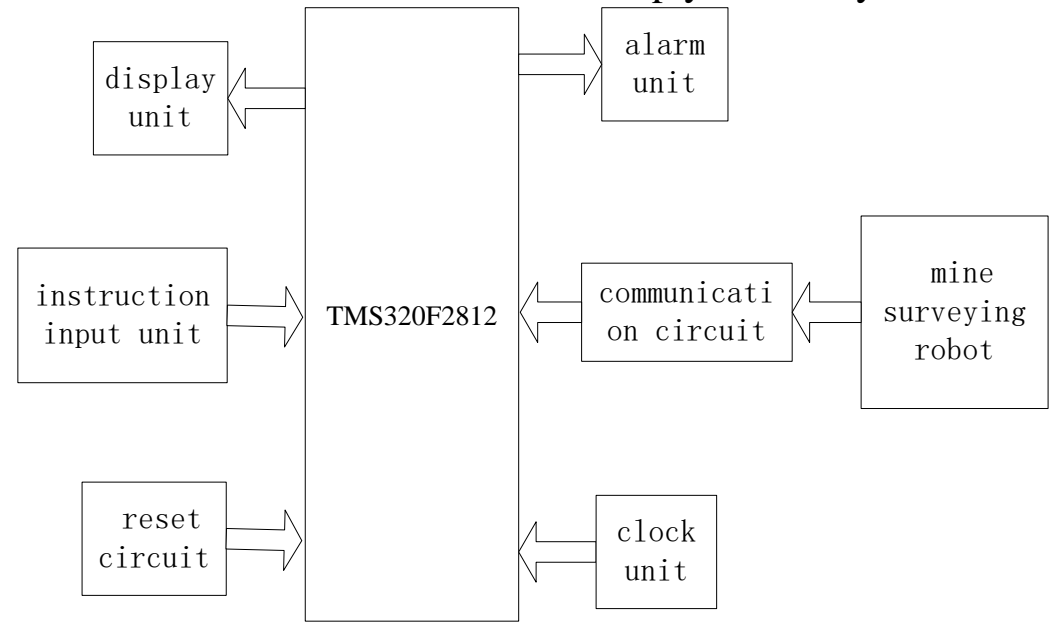

Figure 2 Communication system structure 
The communication system circuit uses the driver chip SP3223EEY of RS-232 standard for data communication. As the chip and TMS320F2812 are both powered by $+3.3 \mathrm{~V}$, the related pins of the chip and TMS320F2812 can be directly connected, and the communication circuit is shown in Figure 1. RS-232 is a physical interface standard of serial bus designated by American Electronics Industry Association (EIA). This standard specifies the mechanical, electrical, functional and process characteristics of the physical connection line between the master control module and the slave module in serial communication, and both ends must follow the common agreement. Its standard bus is 25 lines, but in practice, the simplified 9-line interface or the 3-line (ground line, sending line and receiving line) transmission mode adopted in this example is often used.

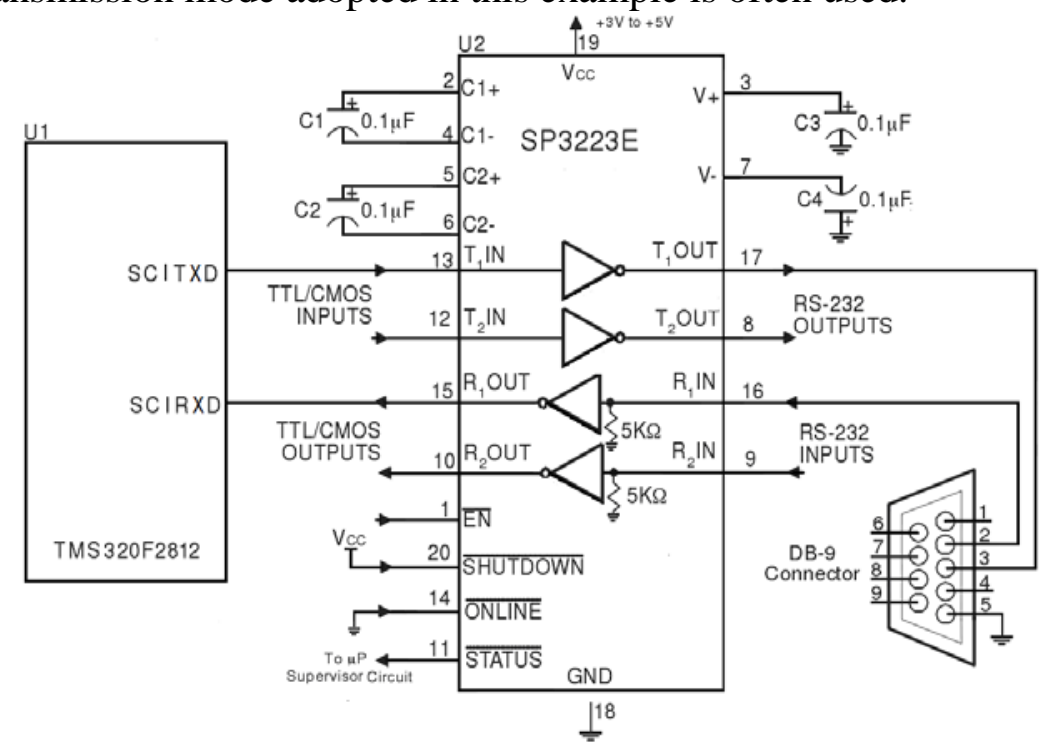

Figure 3 Communication circuit

\section{Conclusions}

The communication technology of mine surveying robot is a comprehensive technology which integrates the measurement principle, power electronic technology and communication theory, and is one of the hot technologies in the field of mine survey. The communication system of mine robot designed with digital signal processor as the core has the characteristics of simple structure, good stability and strong anti-interference ability, which improves the intelligent level of mine survey technology and lays a foundation for the development of mine safety production.

\section{References}

[1] GENG Wei, LU Yong. The cause analysis and treatment of a inner discharge case caused by moistened 35kV switchgear. Electric Switchgear, No.4, 65-66,2008(4).

[2] Aimin Liu, Jiajue Li, Yongxiang Li et al. Motion Control System Simulation of Cylindrical Linear Induction Motor used in Circuit Breaker Operating Mechanism. ICAL 2009, s henyang, 460-464, 2009.

[3] Xin Lin, Huijun Gao, Jianyuan Xu. The calculation and analysis of the coupled problem in the permanent magnetic actuator for vacuum circuit breaker. Digests of the 9th Biennial IEEE Conference on Electromagnetic Field Computation (CEFC)296,2000.

[4] YU Qing-rui, MA Zhi-ying, SHI Rui-lin. Eiectric field analysis and structure optimization of the wall bushing of 40.5kV C-GIS. Hua Tong Technology, No.3,7-10, 2005.

[5] Xin Lin, Deshun Wang, Jianyuan Xu, Yueqian Ma. Application of Single Neuron PID Controller in Movement Control of High Voltage Circuit Breaker.Transactions of China Electrotechnical Society, vol.1, 1-7,2009. 
[6] YAN Qun. Design and analysis of insulation structure of solid insulation switchgear. Mechanical Research \& Application, No.5,77-80,2009.

[7] XU Guo-hao. High voltage switchgear insulation accident's analysis and countermeasures. China Science and Technology Information, Vol.14:94-95, 2006.

[8] Xiao-yu Wang, Xin Lin, Jian-yuan Xu, Yong-xiang Li. Research on the Control Technique of the Permanent Magnet Linear Servo Motor Operating Mechanism of High-voltage Circuit Breaker. ICAL,Shenyang.465-470,2009.

[9] LU Ming, YAN Dong, YANG Qing. The effect of error installation of grading ring on electric field distributions. Insulators and Surge Arresters, vol. 2,1-3, 2010.

[10] GE Dong, MAO Yan, HE Zi-ming, et al. Calculation of power frequency voltage and electric field distribution on $110 \mathrm{kV}$ composite insulators with parallel gap. Insulators and Surge Arresters, vol. 5:26-30,2011

[11] LU Ming, YANG Qing, YAN Dong, et al. The effect of the composite snsulators sheds type structure on the electric field distributions. Insulators and Surge Arresters, vol.1,1-6,2011.

[12] HAN She-jiao, MA Xi-kui, GUO Guo-ling. Electrical fields computation of tank type metal-oxide surge arrester for 110kV GIS. Insulators and Surge Arresters, No.1,33-35,2002.

[13] WEN Kang-zhen, WEN Yuan-fang, DUANMU Lin-nan, et al. The error of ANSYS solution of electrostatic field produced by sharp electrode. Insulators and Surge Arresters, No.2,14-16,2009.

[14] DANG Zhen-ping, PEN Zong-ren. Errosion test on 500kV composite rod insulator fractured in service and its electric tress estimation. Insulators and Surge Arresters, No.4,1-7,2005.

[15] Xin Lin, De-shun Wang, Jian-yuan Xu. Linear Servo Motor Operating Mechanism and Control Technique for High-voltage Circuit Breaker. Proceedings of the CSEE, vol.27,pp. 137-141,2008.

[16] GAO Bo, ZHANG Ya-ting, WANG Qing-liang, et al. Effect of pollution non-uniformity on electric field of contaminated insulator. Insulators and Surge Arresters, No3,13-16,2008.

[17] Yongxiang Li, Xin Lin, Jianyuan Xu. Design of a Novel Permanent Magnet Brushless DC Motor-Driven Operating Mechanism for High-Voltage Circuit Breaker and Its Dynamic Simulation. Power System Technology, vol. 1, 185-189,2010.D. Z. Cheng, Controllability of switched bilinear systems, IEEE Trans. on Automatic Control, Vol.50, No.4, 511-515, 2005. 